\title{
OS TEMPOS DIFERENCIADOS
}

José Luiz Martins Nunes*

\author{
"Para o historiador, \\ tudo começa e tudo acaba \\ pelo tempo" \\ Fernand Braudel
}

\section{HISTORIOGRAFIA DO TEMPO}

Não pretendemos falar do tempo como um todo, mas da nossa visão do tempo. Entretanto não podemos ignorar a importância do tempo na história. O tempo é o contexto da história. O filósofo e historiador Johann Herder já se preocupava com o tempo, dizendo que "a formação de um reino depende, primordialmente, do TEMPO e do lugar em que nasce, das partes que o compõe e das circunstâncias exteriores que o rodearam". ${ }^{1}$ Para Herder, o tempo só coexiste coletivamente. Não há tempo do indivíduo, tampouco tempo antropológico, apenas tempos urbanos ("urbs temporum") e institucionais: "se um povo ficou isolado, seu caráter individualizou-se e diluiu-se nas mãos do tempo". ${ }^{2}$ O tempo em seu conluio com a história adquire várias

* Livre Docente em História, Professor Adjunto da ULBRA.

1 HERDER citado por GARDINE, Patrick. in Teorias da História. Fundação Calouste Gulbenkian, Lisboa, 1984, p. 43.

2 Idem, p. 52.

Estudos Ibero-Americanos. PUCRS, v.XXI, n.1, p. 85-96, julho, 1995 
nterpretações. Para Condorcet "o tempo se confundia no progresso do espírito humano". 3

Neste ensaio, pretendemos discutir o tempo e a história, buscando fontes na histografia e nas teorias da história. Observamos que a questão temporal já preocupa dois pensadores do quilate de Herder e Condorcet, no séc. XVIII, o tempo, na verdade, sempre preocupou o homem. Santo Agostinho perguntava-se o que estaria fazendo Deus no TEMPO anterior ao da criação da terra e do homem. ${ }^{4}$ Mas, sendo o tempo a principal preocupação do historiador e do filósofo - no sentido de tempo "realização de algo" - o "ohronon" dos gregos significava não só o passamento físico, mas a temporalidade psicológica. ${ }^{5} \mathrm{O}$ principal objetivo deste trabalho é mostrar os "tempos diferenciados" em que a história, em seu conceito clássico - "estudo do passado" ${ }^{16}$ - transcende o conceito e rasga os limites do passado, aparecendo no presente. Brauciel, o notável artífice de "le longue durèe" já dizia que "o tempo de hoje quase não se compreende, a não ser ligado ao tempo de amanhã"7 e que "a história é ao mesmo tempo conhecimento do passado e do presente, do 'tornado' e do 'tornar-se', distinção em cada tempo histórico"."

A história se faz presente na diferenciação do tempo; desde o fim do séc. XIX, ela vem se libertando dos "tempos estáticos". Os annales realmente significaram a extrapolação da história, que passa a acontecer sempre em todos os momentos, "o antigo regime não acaba em nenhum lugar, em nenhum momento" já firmava Pierre Chaunu' e esta dinâmica desafia a temporalidade que sucumbe à totalidade da história. Febvre já dissera que "a história é a ciência do passado, ciência do presente" ${ }^{10}$ e ao abrir sua obra singular (à guisa de conclusão de uma carreira?) o grande

3 CONDORCET in GARDNER, Patrick. Obra citada, p. 64. A visão do tempo para Condorcet era filosófica; o tempo da história adquiria um devir positivo face às conquistas políticas do povo e um devir negativo se o "nefando" absolutismo permanecesse à testa do Estado - como permaneceu - no séc. XVIII.

AGOSTINHO, Santo. Confissões. E. Vozes, Rio de Janeiro, 1988, p. 61.

5 BORHEIM, Gerd. Os Pré-Socráticos. Ed. Cultrix, Rio de Janeiro, 1984, p. 13.

6 SEIGNOBOS \& LANGLOIS. Introdución a los Estudos Históricos. Editorial La Plêyade, Buenos Aires, 1961.

7 BRAUDEL, Férnand. Escritos sobre a História. Ed. Perspectiva, São Paulo, 1981. p. 14 e seg.

8 BRAUDEL, Férnand. História e Ciências Sociais. Ed. Presença, Lisboa, 1983. p. 20.

9 CHAUNU, Pierre. História como Ciência Social. Ed. Zahar, Rio de Janeiro, 1981. p. 64.

10 BRAUDEL, op. cit., p. 22. 
historiador sentencia: "nada de regressar ao passado, nada de regressar a mim mesmo..."11 Ora, qual é o tempo de Febvre? Michelet, Carlyle e até Varnhagen estariam surpresos! Um historiador que nega o passado não pode ser historiador! E para culminar, Febvre declara seu amor pela história e diz que faz da vida uma incessante busca. ${ }^{12}$ Na verdade, Febvre junto com Marc Bloch ${ }^{13}$ foi o primeiro historiador a reconhecer a força da história. "A história tem seu próprio tempo" ${ }^{14}$ reconhece Glenisson e, no entanto, ouso afirmar que a história não precisa de tempo! E tampouco o tempo precisa da história porque ambos coexistem, se completam e vivem independentes um do outro. $\mathrm{O}$ tempo como tal, cronológica e espacialmente, conforme concebemos no nosso dia-a-dia, não existe para a história. O povo, em nível de massa popular, desconhece a história tanto quanto o tempo da história. O seu tempo é o tempo das tarefas cotidianas, o tempo (ou a "hora") de levantar para ir ao trabalho, do almoço, de largar o serviço, dos fins de-semana, de visitar a mãe, ou a sogra, convenhamos, isso é o "tempo histórico"?

O tempo da história não é cotidiano, é fascinante; engloba toda experiência vivenciada pelo historiador. O tempo do Egito, aquele témpo cronologicamente milenar, cai na fantasia das coisas improváveis; não estamos duvidando da história egípcia, estamos questionando a validade da objetividade de 3.200 anos AC. É a mesma sensação (ou seria sentimento?) de se ouvir falar que alguém tem cinco bilhões em dinheiro, pois a extrapolação do limite de nossa imaginação compromete a realidade. Já o tempo da Revolução Francesa tem outra postura, é um tempo palpável, pois sabemos efetivamente o que ocorreu em 14 de julho de 1789 , há testemunhos, há documentos e há, inclusive, historiadores! ${ }^{15} \mathrm{O}$ tempo contemporâneo é o que há de mais palpável incluindo-se aí a própria visualização geográfica do mesmo. Existem registros, filmes e fotos para atestarem os fatos. Basta ver os telejornais da época da $\mathrm{II}^{\mathrm{a}}$ Guerra Mundial para saber que o dia 6 de junho de 1944 (Dia "D") amanheceu chuvoso e nebuloso a ponto do General Eisenhower pensou em adiar a "Operação Overlord".

11 FEBVRE, Lucièn. Combates pela História. Ed. Presença. Lisboa, 1983, p.

12 Ibidem, p.

13 BLOCH, Marc. Introdução à História. Ed. Europa-América, Lisboa, 1980.

14 GLÉNISSON, Jean. Introdução aos Estudos Históricos. Ed. Difel, São Paulo, 1979.

15 Podemos citar Mirabeau e Edmund Burke, historiador inglês contemporâneo da Revolução Francesa (BURKE, Edmund. Reflexões sobre a Revoluçäo em França. Ed. UNB, Brasília, 1984, a primeira edição inglesa foi lançada em 1790). 
Dando seqüência à historiografia do tempo, um tanto já filosófica - "a filosofia e a história se completam", Marrou ${ }^{16}$-, afirmamos ser o tempo da história o tempo do historiador. Cada historiador vê a história de uma maneira e, logicamente, observa e delineia o tempo de SUA história à SUA maneira. Não foi por acaso que, numa antevisão, Tolstoi referiu que "o tempo tem força em relação à ótica humana". ${ }^{17}$ Entretanto, Blake indaga-se com muita propriedade, "como podemos nós saber que as coisas foram como nós pensamos que foram?"18 Este problema, o da objetividade, (poderá a história ser objetiva?) pergunta Blake ${ }^{19}$ é, em sua essência, epistemológico e por isso a objetividade do tempo histórico se relaciona com a objetividade da visão do mundo do historiador. Objetivamente eu, como historiador, tenho meus conceitos (e preconceitos), minhas idéias (ideologias é um termo desgastado e perigoso), enfim, meu posicionamento, o meu tempo histórico está ligado à minha concepção e compreensão da história.

O tempo da história espelha a concepção do historiador. Voltemos a Braudel. ${ }^{20} \mathrm{O}$ tempo de Braudel é o da longa duração, pois "na longa duração todo trabalho histórico decompõe o tempo passado e escolhe as suas realidades cronológicas, segundo preferências e exclusões mais ou menos conscientes". ${ }^{21}$ As preferências citadas pelo mestre francês são de quem? E as realidades cronológicas? São ambas do historiador, evidente. É Braudel, na sua ótica humana (eis a validade da afirmativa de Tolstoi) que cria a longa duração e a desenvolve, recriando o tempo da média e da curta duração. Entretanto, a longa duração - é a dúvida que me assalta - é a duração do tempo histórico, dos fatos humanos, ou naturais? Em sua monumental obra "O Mediterrâneo no tempo de Felipe II"22 ele deixa claro o alcance da longa duração. Ele se encontra no clima, na hidrografia, no mar: "O homem, há séculos, é prisioneiro dos climas, das vegetações, das populações animais, das culturas...", ${ }^{23}$ a longa duração

16 MARROU, Henri I. Sobre o Conhecimento Histórico. Ed. Zahar, Rio de Janeiro, 1978. p. 10.

17 TOLSTOI, Léon. A Dificuldade de Definir as Forças. in GARDINE, Patrick, op. cit. p. 205.

18 BLAKE, Cristopher. Poderá a História ser Objetiva? idem p. 403.

19 Ibid p. 404 e seg.

20 BRAUDEL, op. cit. p. 7.

21 Idem, p. 31-34.

22 BRAUDEL, Fernand. O Mundo Mediterrâneo no Tempo de Filipe II. Ed. Martins Fontes, São Paulo. 1983.

23 BRAUDEL, op. cit. p. 11. 
está aí. Ela mostra o tempo que atravessa os séculos e desafia o homem. $\mathrm{O}$ frio que sentimos hoje, Felipe II sentiu; apesar das transformações sociais, econômicas e técnicas, o frio existe e, em sua essência epidérmica, continua o mesmo. A ação do homem face às vicissitudes naturais pode abrandá-las, mas não as anula e é nessa impossibilidade, nessa imobilidade que resulta o tempo longo. O tempo médio e curto mostra o homem triunfante, a própria narrativa das teorias braudelianas adquire outro fôlego. O homem não mais é esmagado pela natureza, ele fez a sua história e o seu tempo. É bom salientar que este homem está em Braudel, é criação sua, assim como qualquer história é criação do historiador.

A partir dos anos 80 surge a "Nova História", idealizada principalmente por Jaques Le Goff e Pierre Nora. ${ }^{24}$ A nova história antropológica que está aberta à todos os temas, além, inclusive, das mentalidades; ${ }^{25}$ reconheçamos que a Nova História se faz pela junção da antropologia com a história, ou, como disse Georges Duby (atualmente o historiador mais representativo da França), "a Nova História é feliz na medida em que estimula, ela leva a desconfiar das rotinas (...). ${ }^{26}$ A Nova História é, a nosso ver, o amadurecimento, a maturidade das mentalidades de Lucién Febvre, Marc Bloch e Braudel. E o tempo, nessa história que se diz nova? O tempo da Nova História é o tempo do fato ou da pesquisa histórica. A longa duração está presente quando a geo-história se faz presente. E a dinâmica dos tempos médios e curtos também se faz presente, só que muito mais presente que nos "Annales", porque o tempo da Nova História é um tempo ligado intimamente à "massa-média" de comunicação. Os recursos técnicos dos meios de comunicação - rádio FM, TV a cabo, videocassete, satélite, etc. - faz com que os tempos e as distâncias desapareçam; um documentário sobre a história da Revolução Francesa (trata-se do tempo passado), pode passar concomitantemente na França e no Brasil, o tempo, portanto, fica reduzido a frações de segundo.

Em meio a todo este progresso, a história tem que se cuidar para não ser pega de surpresa. Seu objetivo principal como ciência é o estudo do conhecimento humano e natural, mas numa ótica em que o tempo passado tenha mais realce que qualquer outro tempo. Nessa época de

24 LE GOFF, Jaques e Pierre. Nova História: novas abordagens, novos objetos, novos problemas. Ed. Fco. Alves, Rio de Janeiro, 1976, 3 volumes. LE GOFF, Jacques, DUBY, Georges, LADURIE, Le Roy e outros. A Nova História. Ediçōes Setenta, Lisboa, 1977.

26 DUBY, Georges. Orientações da pesquisa histórica na França. in Idade Média/Idade dos Homens. Ed. Companhia das Letras, Rio de Janeiro, 1989. p. 207. 
avanço tecnológico, em que o computador já se inseriu no cotidiano do historiador, ele tem que estabelecer limites entre a tecnologia e os velhos instrumentos de pesquisa. A história de "cola e tesoura", no dizer de Colingwood, ${ }^{27}$ continua sendo importante, pois o passado, o tempo da história, tem que estar em contato direto com o historiador. Para nós é inconcebível que um historiador, no futuro, seja um homem cercado por artefatos tecnológicos e se distancie decisivamente do documento. ${ }^{28} \mathrm{O}$ historiador que se distancia de seu objeto de pesquisa deslustra sua tarefa e afasta-se da sua função: construir o seu tempo na história.

Todavia, não sejamos tão drásticos. A técnica será aliada das velhas armas e o tempo, distante desse embate, será longo, médio, curto, curtíssimo conforme sua intensidade na pesquisa e conforme, também a ótica em que o historiador lhe estará olhando e construindo.

Não conhecemos uma "historiografia do tempo salvo algumas incursões de caráter introdutório, ${ }^{29}$ a história como um todo. É verdade que a antigüidade ficou de fora desta análise; tal lapso se justifica por dois motivos: primeiro, porque entre os historiadores da antigüidade não sabemos se havia consciência da história, ${ }^{30}$ essa consciência começa com João Batista Vico, com "A Ciência Nova", e, em segundo lugar, nosso objetivo foi elaborar uma historiografia que não ficasse atrelada às ortodoxias cronológicas, inclusive porque o objeto deste ensaio - o tempo - é bastante abstrato e afactual.

\section{A TEORIA DO TEMPO HISTÓRICO}

A história concebe o tempo de forma ativa, mas essa característica está umbilicalmente ligada à dinâmica interna do fato histórico. Deixamos claro que fato histórico é todo aquele acontecimento, situação ou

27 COLINGWOOD, R. G. A Idade da História. Ed. Presença, Lisboa, 1981.

BARRACLOUCH, Geoffrey. O documento é a alma do historiador. in Past and History. p. 126.

29 Como as obras de GLÉNISSON, Jean. Iniciação aos Estudos Históricos, Ed. Difel, São Paulo; GARDINER, Patrick. Teorias da História (op. cit.) esta obra faz algumas referências ao tempo e à história. BESSELAAR, Van Den. Introdução aos Estudos Históricos, EDUSP. 1972. e BLOCH, Marc. Introduçāo à História. Ediçōes EuropaAmérica, entre outras tantas obras.

30 PLATÃO teria tido "inconscientemente" uma consciência histórica n'A República. TUCÍDIDES fazia uma História-testemunho e talvez apenas TITO LÍVIO fez uma História de Roma com atilada consciência histórica. 
circunstância que é examinado pelo historiador. O acontecimento que for objeto de estudo, análise ou curiosidade de um historiador é um fato histórico.

O tempo em história transcende os limites geográficos, cronológi$\cos$, meteorológicos, filosóficos etc. Porque sua realidade é de um tempo que já passou e que, peculiarmente, sempre volta a ser presente. Volta a estar presente pela mão do historiador, ajudado pelo avanço da técnica "stricta" e "latu". ${ }^{31} \mathrm{O}$ passado torna-se presente pela forma mais usual e primitiva $^{32}$ através da reprodução simples da situação passada como uma fotografia. Um filme, um documentário já se faz de forma mais elaborada. E a associação do historiador ao recurso torna a história mais presente ainda.

A Teoria do tempo em história ocorre a partir de um "ato de fé". O historiador é como um sacerdote. Tem que acreditar que o Imperador Tito Vespasiano nasceu a 30 de dezembro do ano de 40 e morreu a 13 de dezembro de $81 .{ }^{33}$ Como se ter certeza? O calendário não era o mesmo, a forma de contar os anos era diferente, até esta problemática de "antes de Cristo" e "depois de Cristo" só foi utilizada muitos anos depois. E, no entanto, gerações e gerações de historiadores repetem estes dados. "O tempo histórico não passa de uma imperfeita cronologia" sentenciou Fustel de Coulanges. Todavia, há a necessidade de recriar-se o tempo histórico, principalmente para explicar a antigüidade e, mais secundariamente, a idade média e períodos mais remotos. ${ }^{34}$ Não obstante, o fascínio da história está nela mesma. A história é a única ciência que utiliza de seu processo posterior estático para desmentir, ou confirmar teorias anteriores. Se a antigüidade e a medievalidade exigem o ato de fé, a época moderna e, mais ainda a contemporaneidade, dispensam o tempo histórico como algo filosoficamente mágico. $\mathrm{O}$ tempo da história contemporânea confunde-se com o tempo comum. Braudel dividiu o tempo em longo, médio e curto a partir do remoto, para o recente. É por isso que existem tantos historiadores contemporâneos, em detrimento dos que

31 Técnica "stricta" é aquela que restringe-se a elementos tão somente tecnológicos (computador, vídeo, carbono 14 ...) e a técnica "latu" é aquela que associa o avanço técnico com o progresso da metodologia e da pesquisa histórica.

$\mathrm{O}$ termo é de DRAY, Wllliam in Filosofia da História. Ed. Zahar. Rio de Janeiro, $2^{\mathrm{a}}$ Ed, 1977, p. 56.

33 Segundo SUETÔNIO. Os doze Césares. Editorial Presença. Lisboa, 1977.

34 A idade média, a partir do séc. X não se depara mais com tantos problemas de datação (cf. DUBY, Georges. O Ano Mil. Edições Setenta. Lisboa). 
abraçam a antigüidade e o medievo; esses abraçam tarefa espinhosa e incerta. Estarão fazendo história os historiadores das épocas mais remotas? Enfrentam percalços quanto à documentação, quanto às lacunas imensas e até quanto a datação. O historiador contemporâneo não concentra o mesmo esforço: os documentos são abundantes, a técnica auxilia, os médicos facilitam, as bibliografias oferecem várias interpretações. E o tempo torna-se curto porque na história contemporânea o passado e o presente fundem-se num tempo histórico muito especial e singular. Um século (1895-1995) não faz efeito algum historicamente. A vida humana tem aumentado sua média ( 77 anos na Europa, atualmente) o que faz crescer consideravelmente a importância dos testemunhos. O historiador contemporâneo é um elemento que porta, indubitavelmente, o gravador nas mãos, quem tem 75 anos hoje relata, com inegável prazer e nostalgia, a sua adolescência de 60 anos passados. O tempo histórico também torna-se presente, de forma emocionante!

É através da história de gravador em punho que chegamos mais facilmente aos tempos diferenciados. O tempo não é apenas idade, tampouco períodos de horas, dias, semanas, meses (...), ele significa acúmulo de emoções, paisagens, pessoas mortas ou envelhecidas ou ainda, extraviadas. O tempo do testemunho é o tempo passado que metamorfoseia o presente. O passado nunca passou, sempre foi presente, é que ele não foi mais evocado e, por isso, só por isso, ficou guardado a espera, à esperança de vir à tona pela mão do historiador, despido de teorias e munido tão somente da poesia do tempo que nunca passou...

A teoria do tempo histórico tem várias faces. Cada uma de acordo com o período histórico que se estuda. O tempo histórico da antigüidade é o mais elaborado, o mais trabalhado e, ainda assim, o mais incerto. $\mathrm{O}$ tempo da história contemporânea já adquire, inclusive, formulações de análise graças a abundância de material que permite diversas teorizações e interpretações. $\mathrm{O}$ tempo da história contemporânea não pertence apenas ao historiador, pertence a quem o testemunhou, ${ }^{35}$ ao jornalista, ao eco-

35 O testemunho guarda a verdade para si e só a revela de acordo com sua emulação. A população alemã com mais de 60 anos não revela (ou o faz após muita insistência) o que testemunhou no período da Segunda Guerra Mundial (1939/1945). Já disse o escritor alemão Heinrich Böll "o silêncio é o seu testemunho". Temos de considerar também que a verdade de um fato ocorrido há 60 anos (por exemplo, o episódio da Lei Seca nos Estados Unidos nos anos 20) fica comprometido pela avançada idade da testemunha em questão (80/85 anos?): o que esta afirma ser verdadeiro pode estar sendo um equívoco provocado pela falta de memória ou confusâo mental. 
nomista... Este tempo "caminha com suas pernas" porque, efetivamente, existe. Os tempos mais remotos são tempos do historiador, não caminham sem estarem amparados pelo historiador, o tempo da antigüidade e da medievalidade (e de alguns acontecimentos dos tempos modernos e contemporâneos, por que não?) só observa de concreto a lacuna e a explicação incompleta, não há fotografia, só esculturas mutiladas, ruínas... O tempo histórico é o tempo passado que precisa - esta é a tarefa do historiador - tornar-se presente, nem que seja em fugazes momentos.

Trazer o passado ao presente e explicar presentemente o passado, eis a tarefa do historiador em qualquer tempo, remoto ou recente; as facilidades de um e de outro são, neste caso, inerentes à tarefa e à missão do historiador.

\section{OS TEMPOS DIFERENCIADOS}

O tempo é o maior desafio do historiador.É um desafio permanente e teimoso. Mesmo entulhado de testemunhos, sempre se tem algo a testemunhar. O historiador sem o tempo não existiria porque é necessário, antes de tudo, existir o tempo para existir o fato histórico e seus personagens. E é necessário que este tempo esteja no passado para existir história, nos diria um filósofo da história. ${ }^{36}$ Não. Não é necessário.

Os tempos diferenciados perfazem uma nova interpretação na teoria e historiografia do tempo da história. ${ }^{37}$ Fazem sobrepor o passado ao presente, no presente! Não há tempo só do presente, ou só do passado; numa mesma circunstância histórica, o passado se transforma em presente. As rupturas do tempo não existem. Entretanto, é necessário o resguardar, o cuidado; os tempos diferenciados são também (e muito mais?) tempos antropológicos. O tempo histórico sempre se enfraqueceu ante o tempo antropológico. Quedou-se ante o perigo da própria inexistência.

Os tempos diferenciados mostram que situações específicas não passaram e que, ao contrário, ainda continuam presente. Braudel diria que este é o tempo, por excelência, da longa duração, tão longa que

36 DE ClCCO, Cláudio. A Dinâmica da História. Ed. Palas Athena. São Paulo, 1985, p. 14 .

37 BRAUDEL, talvez inadvertidamente, passou ao largo da especificidade desta problemática em seu texto "História e tempo presente" na obra Escritos sobre a História. Ed. Perspectiva, São Paulo, 1978. 
desconhece a divisão do passado-presente. Diríamos que os tempos diferenciados, ${ }^{38}$ para se encaixarem na teoria brudeliana, teriam que ser de longuíssima duração. Para fazer volfar alguns elementos específicos da história egípcia de 4.500 anos atrás, basta ir ao mesmo local. A história ali não aconteceu. A duração do tempo é inerte, quase parada. E lá então, num desafio ao próprio presente, os felás, com seu trabalho agrícola, com seu sorriso tímido, com suas vestimentas típicas. O felá é o que de mais egípcio restou após tantas invasões e miscigenações etno-culturais. Eis o tempo diferenciado no seu exemplo talvez mais importante e mais absoluto. Um passado de 4.500 anos está no presente, imutável. O tempo não existe. A história é presentista nos tempos diferenciados, não da maneira como Benedetto Croce a viu ${ }^{39}$ e sim do passado revelando-se no presente, sem ser trabalhado pelo historiador.

Há que se perguntar: e o elemento antropológico? Claude LéviStrauss, na sua famosa antropologia estrutural, coloca que a antropologia desconhece o tempo quando trata-se de estudar as culturas em sua evolução estrutural". ${ }^{40} \mathrm{O}$ tempo antropológico é, basicamente, o tempo diferenciado. Existem inúmeros exemplos: os índios na América conservam seus rituais, modos e meio de vida; nativos das Filipinas vivem na Idade da Pedra e tribos no interior da África praticam rituais que estudiosos consideravam extintos há mais de 2.000 anos! São civilizações (ou são culturas?) ${ }^{41}$ que praticam "atos culturais" supostamente extintos pelo tempo presente, mas que a antropologia e os tempos diferenciados - passado sobre o presente - confirmam como existentes e importantes, como luminares atuais de estudo para cientistas sociais.

$\mathrm{Na}$ história brasileira encontramos fora do contexto indígena alguns exemplos de tempos diferenciados contemporâneos (muito raros). Viajando por este imenso país, podemos encontrar o lavrador em meio

38 Tempos diferenciados porque sobrepõe passado e presente numa mesma situação histórica não existindo - repetimos - tempo único (presente apenas) e sim dois tempos: passado e presente.

39 CROCE, Benedetto. A História como Pensamento e Ação. Ed. Zahar. Rio de Janeiro, 1962.

40 LÉVI-STRAUSS, Claude. Antropologia Estrutural. Ed. Zahar. São Paulo, 1975, e A Oleira Ciumenta. Ed. Brasiliense. São Paulo, 1984, e ainda, A Via das Máscaras. Ed. Presença. Lisboa, 1986. Toda a obra de Lévi-Strauss é importante na questão da antropologia estrutural, cultural e do gesto.

41 A questāo conceitual de Civilização e Cultura é demasiado longa e complexa para tratarmos aqui; ler KAPLAN e MANNERS. Teoria da Cultura. Ed. Zahar. Rio de Janeiro, 1981. 
a "Casa Grande" de séculos atrás. E podemos reconstituir facilmente a paisagem; não raro o lavrador é negro e lá está, agachado, colhendo ou semeando, ou garimpando o solo. Mudou apenas o substrato jurídico. O negro não é mais escravo, mas continua - ainda que em poucos exemplos interioranos - no mesmo panorama da Casa Grande ou da fazenda. ${ }^{42}$

Os tempos diferenciados, todavia, têm facilidade para espraiaremse. Na Europa, quando ocorre um casamento real, ${ }^{43}$ todas aquelas pompas fazem os espectadores recuarem para os séculos XVIII e XIX. O presente desaparece ante protocolos seculares.

Também nas ciências jurídicas e no Direito Constitucional o passado permanece presente. A Magna Carta Inglesa (de 1215) e a Constituição Americana (1776) continuam a ser presente. E são muitos os países que conservam Códigos Civis e Penais inalterados por séculos. São exemplos que, desvinculados da antropologia e extremamente contemporâneos, consagram a pacífica intromissão do passado no presente consagrando, por sua vez, os tempos diferenciados.

Outra questão pertinente é a que se segue: como o historiador trabalha os "tempos diferenciados"? Metodologicamente, não existe uma técnica para apurá-los. A base teórica de compreensão encontra-se em obras que analisam a cultura e a antropologia cultural, social, filosófica e estrutural. Citamos Claude Lévi-Strauss, como poderíamos citar Leroi Gourhan, Malinowski, ou os historiadores Carlo Ginzburg, ${ }^{44}$ Roberto Darnton $^{45}$ ou Alain Corbin, ${ }^{46}$ além do grande Phillipe Ariès. ${ }^{47}$ Não esquecemos nosso modesto ensaio (uma proposta acerca do assunto nunca estudado) sobre a história da voz. ${ }^{48}$ Estes trabalhos estão vinculados à história das mentalidades e à nova história, estas correntes da historiografia recente mantém um vínculo com a antropologia. O moleiro de Ginzburg é uma figura ainda existente nos confins interioranos da Itália. E o problema da fé ainda existe sob outros moldes. A interpretação

42

Nota-se esta paisagem no Vale do Paraíba, no sertão pernambucano, no pampa gaúcho, na zona cafeeira de Ribeirão Preto, dentre outros lugares do Brasil.

Como o da Princesa Diana e o Príncipe Charles, na Inglaterra, em junho de 1981.

GINZBURG, Carlo. O Queijo e o Vern:e e Os Andarilhos do Bem. Ed. Companhia das Letras, São Paulo, 1988.

DARNTON, Robert. O Grande Massacre dos Gatos. Ed. Graal. São Paulo, 1986, e Boêmia Literária e Revolução. Ed. Companhia das Letras. São Paulo, 1988.

CORBIN, Alain. Saberes e Odores. Ed. Cia. das Letras. Sāo Paulo, 1987.

ARIÈS, Phillipe. História Social da Criança e da Família. Ed. Zahar. Sāo Paulo, 1982, e História da Morte no Ocidente. Ed. Gradiva, Lisboa, 1989.

NUNES, José Luiz Martins. Ensaio Inédito sobre a História da Voz. s/d. 
dos contos infantis do "Chapeuzinho Vermelho" que Darnton focaliza no "Grande Massacre dos Gatos", mantém-se atual com outros personagens, como o Super-Homem, Tio Patinhas, Pato Donald... E a boêmia literária do séc. XVIII não conhece dois séculos de distância: poetas, escritores, marginais existem às mancheias. Os "Saberes e Odores" de Corbin mostram que o problema da ablução, dos maus odores e da desodorização sempre existem e existirão. A morte vista por Philipe Ariès mostra que, inobstante a modificação da visão da morte, as exéquias permanecem as mesmas a dezenas de séculos, particularmente a vinculação dela com a religião. ${ }^{49}$

Os tempos diferenciados rasgamos limites do tempo curto quando vinculam-se com a antropologia estrutural e com a história das mentalidades. Sua complexidade e fascínio está em trabalhá-los através das mentalidades. ${ }^{50} \mathrm{O}$ passado torna-se presente nas atitudes do camponês, do boêmio literário, da reação à morte e de tantas outras relações humanas inesgotáveis e transcendentes ao tempo.

Portanto, o passado não é algo amorfo e distante em relação ao presente. Se bem trabalhado pelo historiador, torna-se presente, e o tempo histórico adquire diversas variáveis ${ }^{51}$ para explicar seu permanente dinamismo e inovação.

49 Esta vinculação aparece no Velho Testamento, no Bagavad-Gita, no Novo Testamento e no Alcoräo.

50 "A história das mentalidades está longe de esgotar-se e oferece muitas oportunidades de novos rumos" in VOLVELLE, Michel.Ideologias e Mentalidades. Ed. Brasiliense, Sāo Paulo, 1987.

51 Os tempos diferenciados são a variável de maior ligaçăo com a antropologia e a história das mentalidades, conforme já foi aventado neste ensaio. 